\title{
HIERARQUIAS E CONFLITOS: REPENSANDO OS ANFITEATROS ROMANOS NO INÍCIO DO PRINCIPADO
}

\author{
Hierarchies and conflicts: rethinking Roman \\ amphitheaters in early Empire
}

Renata Senna Garraffoni*

\begin{abstract}
RESUMO
O presente artigo tem como objetivo discutir interpretações recentes acerca dos anfiteatros de pedras romanos erguidos no início do Principado. A partir da relação entre cultura material e fontes escritas procuraremos discutir estas abordagens buscando maneiras mais plurais para se pensar a cultura e identidade romana.
\end{abstract}

Palavras-chave: anfiteatros romanos, identidade, cultura e poder.

\begin{abstract}
This paper aims at discussing recent studies on stones amphitheatres built in early Empire. I will focus my analysis in the way these arguments were constructed, especially in what concerns about the relationship between material culture and written sources, to try to propose more pluralist approaches to the Roman culture and identity.
\end{abstract}

Key-words: stone amphitheaters, identity, culture and power.

* Doutora em História pelo IFCH/Unicamp, Professora do Departamento de História da Universidade Federal do Paraná (UFPR), pesquisadora associada do NEE/Unicamp e CPA/Unicamp (resenna@hotmail.com). 


\section{Introdução}

Ao longo destes anos de pesquisa sobre a gladiatura romana, um aspecto sobre os combates chamou nossa atenção em particular: a diversidade. Além da grande quantidade de fontes escritas e vestígios materiais produzidos por mais de cinco séculos em que se realizaram os combates, destacamos a sua permanência no imaginário ocidental.

Mesmo que os gladiadores tenham sido extintos, definitivamente, por volta de 438 d. C., suas façanhas não desapareceram por completo. Estas experiências de vida, tão distintas de nossas sensibilidades modernas, foram "resignificadas" nos séculos que seguiram a extinção dos combates, seja por meio dos relatos milagrosos dos mártires cristãos que pereceram nas arenas ou no reaproveitamento das estruturas anfiteatrais para a construção de monastérios ou Igrejas no período Medieval.

Estudos da arquitetura romana do período Renascentista ou mesmo em épocas mais modernas, como as miniaturas do Coliseu realizadas desde o século XVIII, ${ }^{1}$ as pinturas realistas de combates do francês Jean-Léon Gérôme do século XIX, ${ }^{2}$ as produções cinematográficas de Hollywood em pleno século $\mathrm{XX}$ ou as exposições de peças em diversos museus, também indicam a força desse fenômeno e a constante reinterpretação do passado romano. ${ }^{3}$

Se por um lado a arte e os estudos arquitetônicos ajudaram a manter viva a memória dos combates, por outro a História e a Arqueologia, desde o século XIX, foram as grandes responsáveis por produzir conceitos interpretativos desse fenômeno e, conseqüentemente, de como a sociedade romana se relacionava com os combates. Dentre os diversos debates acadêmicos que se estabeleceram sobre o complexo mundo da gladiatura romana, optamos

1 Sobre as miniaturas e modelos do Coliseu, ver, por exemplo:

CONTI, C. Il modello lígneo dell'anfiteatro Flavio, di Carlo Lucangeli: osservazioni nel corso del restauro. In: LA REGINA, A. (Org.). Sangue e arena. Roma: Electa, 2001, p. 117-125.

SCHINGO, G. I modelli del Colosseo. In: LA REGINA, op. cit., p. 105-115.

2 Sobre as pinturas de combates de gladiadores de J.L. Gérôme, ver. ACKERMAN, G.M. La vie et l'oeuvre de Jean-Léon Gérôme. Paris: ACR Édition, 1986.

3 Alguns pesquisadores têm organizado exposições, catálogos ou artigos que procuram tornar pública esta diversidade de documentação material sobre os gladiadores, ver, por exemplo:

BELTRÁN MARTÍNEZ, A.; BELTRÁN LLORIS, F. La 'epigrafia anfiteatral. In: El anfiteatro de Tárraco - estudio de los hallazgos epigráficos. Tarragona: Grafica Gabriel Gibert, 1991, p. 25-27.

BLANCO FREIJEIRO, A., Mosaicos romanos con escenas de circo y anfiteatro en el Museo Arqueologico Nacional. In: Archivo Español de Arqueologia. Madri, 1950, p. 127-142. Tomo XXIII.

BLÁZQUEZ, J. M., Representaciones de gladiadores en el museo Arqueológico Nacional. In: Zephyrus, IX, Salamanca, 1958, p. 79-94.

KÖHNE, E., Gladiators and the Caesars - the power of spectacle in Ancient Rome. In: Minerva, v. 11 , n. 3, 2000, p. 34-36.

LA REGINA, op. cit. 
analisar, neste artigo, o local em que se davam tais espetáculos, isto é, os anfiteatros de pedra erguidos durante o início do Principado. ${ }^{4}$

A escolha desse tema nos pareceu apropriada para refletirmos sobre cultura, poder e identidade pois, como nos lembra BOMGARDNER, tais edifícios ainda hoje são alguns dos mais significativos da arquitetura romana. ${ }^{5}$ Discutir as antigas arenas e seu papel nas cidades romanas tem se mostrado um caminho profícuo para repensarmos as relações sociais e os conflitos advindos das relações entre os romanos e os nativos das diversas regiões conquistadas. São essas questões que iremos explorar com mais detalhes nas páginas seguintes.

\section{Arenas antigas, olhares modernos}

Há, basicamente, dois tipos de estudos sobre os anfiteatros romanos: um que lida, exclusivamente, com aspectos arqueológicos dos edifícios e outro que procura relacionar fontes escritas com os vestígios dessas estruturas. Com relação aos primeiros, GOLVIN, estudioso francês e organizador de um dos mais completos catálogos sobre os anfiteatros romanos, nos apresenta suas principais tendências. ${ }^{6}$

De maneira resumida, poderíamos dizer que as primeiras tentativas de listar os anfiteatros romanos foram feitas ainda no século XIX, nos grandes dicionários. ${ }^{7}$ No entanto, tais verbetes acabam por unir edifícios de caráter "misto" 8 aos anfiteatros e não havia estudos sobre esses monumentos como um todo. Em geral eram elaboradas descrições monográficas dos edifícios e somente a partir de 1930 os pesquisadores começam a analisar o funcionamento de suas estruturas.

Nesse processo, o ano de 1950 torna-se um marco importante, pois é a época em que se inicia o estudo de estruturas específicas, como o sistema de evacuação da água ou o funcionamento do uelum. ${ }^{9}$ Muitos desses estudos ainda

4 Optamos por analisar aqui somente os anfiteatros de pedras, mas lembramos que havia também arenas de madeira improvisadas nos fora das cidades romanas. Sobre esta questão, ver, por exemplo, GOLVIN, J-C. L'Amphiteatre Romain - Essai sur la théorisation de sa forme et de ses fonctions. Paris: Publications du Centre Pierre Paris, 1988.

5 BOMGARDNER, D.L. The story of the Roman amphitheater. Londres: Routledge, 2002.

6 GOLVIN, op. cit.

7 Cf, por exemplo, THIERRY, C. Amphiteatrum. In: DAREMBERG-SAGLIO. (Orgs.). Dictionnaire des Antiquités Grecques et Romains, Paris: Librairie Hachette, 1877, p. 241-247. Tomo I.

8 Edifícios que funcionavam como teatros e anfiteatros, comuns na parte Oriental do Império.

9 Espécie de toldo que protegia a platéia do sol. 
são produzidos atualmente e visam a elaborar monografias que descrevem e traçam a evolução e as transformações desses edifícios ainda em período romano.

Entre os estudiosos que trabalham diferentes categorias documentais, isto é, fontes escritas e os anfiteatros, predominam modelos interpretativos que visam a enfocar as relações sociais. Neste sentido, optamos por apresentar as matrizes teóricas desses estudos, para em seguida analisarmos como esses autores articulam a cultura material e as fontes escritas.

Iniciemos pelo artigo "The ideology of the arena", de GUNDERSON. ${ }^{10}$ Logo nos primeiros parágrafos ele afirma que sua postura teórica inclui a idéia de tecnologias de poder, usada no sentido foucaultiano, aliada ao conceito de reprodução social de Althusser e à dimensão teatral da civilização romana defendida por DUPONT. ${ }^{11}$ Em poucas palavras, já no início do artigo somos apresentados à interpretação do anfiteatro como um local de transmissão de ideologia.

Neste sentido, utilizando-se principalmente de um arcabouço teórico empregado para o entendimento e crítica da sociedade capitalista, Gunderson afirma que:

Estou propondo a arena como um Aparato Ideológico do Estado em Roma e, além disso, um veículo para a reprodução da relação de produção. Mais importante, a arena serve para reproduzir o sujeito Romano, por meio de atos, como um instrumento de Romanidade, como uma experiência vivida e variada. A arena deveria ser vista como um instrumento ativo, entre inúmeras outras funções ideológicas, para sustentar e gerar a estrutura social romana. ${ }^{12}$

Nesse trecho, o classicista define "Aparato Ideológico do Estado" como meios pelos quais a ideologia romana alcançava toda a população. Neste sentido, interpreta a arena como um instrumento de reprodução e perpetuação dos ideais dessa sociedade, isto é, como uma instituição de Romanização. Em seu argumento, os espetáculos que nelas eram organizados tornavam evidente a ordem social estabelecida ou, em suas palavras, demonstravam o que era “... uma vida romana normal e saudável...". ${ }^{13}$

10 GUNDERSON, E. The ideology of the arena. In: Classical Antiquity, v. 15, n. 1, 1996, p. 11311 Ibid., p. 115-119. As traduções dos trechos das obras em línguas estrangeiras são de nossa autoria. 
Além de tornar visível as hierarquias sociais e de moldar o caráter do Imperador como virtuoso, em oposição ao gladiador bárbaro que merecia a morte, o anfiteatro teria uma outra função, a de sustentar estruturas de poder, por serem erguidas na grande maioria das províncias romanas. Mas como poderiam exercer este último papel? A resposta que Gunderson nos apresenta reside na estrutura física do anfiteatro: a maneira como as arquibancadas eram construídas, com locais demarcados de acordo com a condição social, evidenciava a estratificação, deixando transparente a posição de cada um na sociedade. O teatro político que ali se estabelecia ainda contava com alguns ingredientes fundamentais, como o crime e sua punição; a relação entre civilização e Império em oposição à barbárie; o domínio da Natureza; a repressão à mulher, já que esta ocupava os lugares mais altos dos anfiteatros e, conseqüentemente, com menor visibilidade; além, é claro, da exibição e exaltação dos ideais de masculinidade no centro da arena, ou seja, força física, coragem e desprezo pela morte, ${ }^{14}$ protagonizada por gladiadores ou uenatores (caçadores de feras que se apresentavam antes dos combates de gladiadores).

Nesse processo, a violência e o exótico ocupavam um locus específico e expressavam o confronto entre o civilizado (cidadão romano) e o bárbaro (criminoso punido ou gladiador infame). Condenar à morte ou conceder a vitória era função da platéia, de acordo com o desempenho de cada um na arena. A glória era concedida a quem conseguisse se aproximar mais desses ideais masculinos, exibindo força e destreza diante das adversidades.

Futrel, embora não utilize o conceito de "Aparelho Ideológico do Estado" definido por Gunderson, também desenvolve um argumento enfatizando a Romanização. ${ }^{15}$ Logo nas primeiras linhas de seu livro, afirma que o anfiteatro, mais do que uma simples estrutura arquitetônica ou lugar de diversão e prática esportiva, estava inserido na dinâmica política e social romana, expressando, assim, um locus de comemoração do passado e criando um ideal de grupo no futuro. ${ }^{16}$

Argumentando a partir de um ponto de vista arqueológico e considerando a estrutura dos anfiteatros, Futrel sugere que esses edifícios públicos romanos ajudavam a identificar e celebrar uma autoridade central, isto é, o Princeps, e legitimar seu status. Nesse ambiente, onde povo e Imperador se encontravam, a plebs se expressaria e interagiria com os ideais de cultura romana ali expostos, formalizando o começo de uma nova identidade pautada em símbolos imperiais concretizados nos combates. ${ }^{17}$

14 Ibid., p. 149.

15 FUTREL, A. Blood in the arena: the spectacle of Roman Power. Austin: University of Texas Press, 1997.

16 Ibid., p. 4 e 6.

17 Ibid., p. 231. 
Embora os argumentos de Futrel sejam um pouco mais flexíveis, pois seu texto gira em torno da construção dessa nova ordem e do papel desempenhado pelo anfiteatro, tanto a classicista como Gunderson apresentamnos uma identidade romana única, baseada no conceito de uirtus, isto é, masculina, militar, ativa e conquistadora como oposição ao derrotado: bárbaro, descontrolado e, conseqüentemente, inferior que deve ser dominado. Neste sentido, à identidade romana, proposta por ambos, está implícito o conceito de Romanização, evocado para justificar o papel civilizador desempenhado pelos anfiteatros durante o Principado. Em outras palavras, por meio da violência e do extermínio físico impõe-se um ideal romano universal que deve ser compreendido e respeitado em todos os recantos do Império.

Gunderson e Futrel não são os únicos que interpretam os anfiteatros romanos dessa maneira. Hopkins, por exemplo, afirma que a arena era uma expressão dramática do poder do Imperador, do confronto entre dominados e dominadores e expor isso era parte da política romana. ${ }^{18}$ Wistrand, por sua vez, é explícito ao enfatizar que os anfiteatros ensinavam o valor da coragem, virtude fundamental para a sobrevivência de Roma. ${ }^{19}$ Já Barton afirma, em diferentes momentos de seu texto, que dualidades como identidade e distinção estavam presentes nos anfiteatros e eram fundamentais para a construção do "ser romano" durante o Império. ${ }^{20}$

Por último, e não menos importante, há o livro de Wiedemann. ${ }^{21}$ Este talvez seja o especialista que investiu com mais profundidade nesse viés interpretativo, argumentando que a violência exibida nos anfiteatros consistia em parte de uma estratégia de domínio e expressão do ethos romano perante os bárbaros conquistados.

Em termos práticos, Wiedemann se baseia somente nos eventos das arenas para organizar sua interpretação. Segundo o classicista, aqueles que pisaram nas areias dos anfiteatros eram, antes de tudo, infames, isto é, homens e, às vezes, mulheres dos mais baixos estratos sociais, escravos e condenados ou livres e libertos desesperados, sem outra alternativa de vida. Assim como Barton, Wiedemann traça um perfil único dos gladiadores como homens sem rostos, perdidos, que, caso provassem lutar com bravura, poderiam readquirir o status e, lentamente, voltariam a ser reconhecidos. Esse processo de busca por

18 HOPKINS, K. Death and Renewal - sociological studies in Roman History. Cambridge: Cambridge University Press, 1983.

19 WISTRAND, M. Entertainment and violence in ancient Rome - the attitudes of Roman writers of the first century A.D., Suécia, 1992.

20 BARTON, C. A. The sorrows of the Ancient Roman; the gladiator and the monster. Nova Jersey: Pinceton University Press, 1993.

21 WIEDEMANN, T. Emperos and Gladiators. Londres: Routledge, 1995. 
fama se dava de duas maneiras: pela morte ou vitória. Se um lutador tombasse com coragem, a ele seria concedida a morte rápida pela espada, privilégio dos cidadãos. No segundo caso, vencendo, conquistaria os corações da platéia e, a cada luta, o perdão da população. ${ }^{22}$

Ter essa lição de força e bravura clara e aprendida seria, portanto, mais uma das funções dos anfiteatros. Por estarem presentes nos mais longínquos recantos do Império, os anfiteatros tornam-se um locus importante na implementação do ethos romano, quase sempre estabelecido pelos historiadores modernos a partir de textos escritos por membros da elite. Futrel, Gunderson, Barton, Wiedemann e Hopkins, cada um a seu modo, tomam os valores das elites romanas presentes nesses textos para interpretar os edifícios, tornandoos um local de exibição da moral, identidade e poder civilizador romano. Assim, de acordo com essa perspectiva, em cada espetáculo assistido impunham-se comportamentos e, por isso, eles seriam símbolos da Romanização.

Estudos recentes, como os de Hingley, têm demonstrado que o conceito de Romanização foi criado por estudiosos modernos e empregado de diferentes formas ao longo do século XX para explicar a expansão e conquista de territórios a partir de Augusto, não sendo, portanto, conhecido em tempos romanos. ${ }^{23}$ Apesar das diferentes facetas assumidas entre os classicistas modernos, no caso específico dos combates de gladiadores, a idéia de Romanização é vinculada diretamente à organização da cidade e, conseqüentemente, da construção do anfiteatro, concebido como um lugar privilegiado para a afirmação e reprodução desse suposto ideal romano de civilidade. Os estudiosos mencionados e aqueles que seguem essa perspectiva analítica apresentam, quase sempre, uma identidade romana única e polarizada, construída a partir de oposições: elite/plebs, civilizado/ bárbaro, ordem/caos, natureza/submissão, fama/infamia, imperador/gladiador.

cf.:

22 Para uma discussão mais detalhada de como Wiedemann apresenta a questão da fama/infamia,

GARRAFFONI, R. S. Bandidos e salteadores na Roma Antiga. São Paulo: Annablume/Fapesp, 2002, em especial p.25-36.

GARRAFFONI, R. S. Gladiadores e Transgressão Social: Algumas Considerações sobre uma Nova Abordagem Social. Boletim do C.P.A., IFCH/Unicamp, ano 4, n. 7, jan./jun. 1999, p.201-208.

23 HINGLEY, R. Roman Officers and English Gentlemen - The imperial origins of Roman Archaeology, Londres: Routledge, 2000. Para críticas a estes conceitos tão arraigados na historiografia, ver, por exemplo: HINGLEY, R. (Org.) Images of Rome: Perceptions of Ancient Rome in Europe and the United States in the Modern Age. Journal of Roman Archaeology Supplementary, Serie 44, 2001; HINGLEY, R. Imagens de Roma: uma perspectiva inglesa. Tradução: Renata Senna Garraffoni. Revisão: Pedro Paulo A. Funari. In: FUNARI, P. P. A. (Org.). Repensando o mundo antigo - Jean-Pierre Vernant e Richard Hingley. Textos Didáticos, n. 47, IFCH/Unicamp, 2002; HINGLEY, R. The 'legacy' of Rome: the rise, decline and fall of the theory of Romanization. In: WEBSTER, J.; COOPER, N. (Orgs.). Roman Imperialism: post-colonial perspectives Leicester, 1996, p. 35-48; JONES, S. The Archeology of Ethinicity: Constructing identities in the past and present. Londres: Routledge, 1997. 
De maneira resumida, poderíamos dizer que a base de tais argumentos identifica os anfiteatros como estruturas rígidas, enfatizando, basicamente, somente dois de seus aspectos: o externo e o interno. Externamente, os anfiteatros romanos seriam monumentos arquitetônicos que simbolizariam civilização e o domínio romano sobre a cidade em que eram erguidos. Internamente, as arquibancadas refletiriam a hierarquia social e o poder romano, que, na prática, punia criminosos ou esmagava os bárbaros, representados ali pelas vestimentas usadas pelos gladiadores. Assim, se por fora os anfiteatros concretizavam a monumentalidade do Império, por dentro deixariam claras as hierarquias e submeteriam os infames a suas regras.

Esse tipo de interpretação é constituído a partir de alguns pilares a que todos os autores recorrem para desenvolver seus argumentos: as leis de Augusto sobre os lugares a serem ocupados, o uso da toga pelos cidadãos registrados por Suetônio ${ }^{24}$ e a estrutura arquitetônica dos edifícios. Se esses elementos permitem a elaboração de interpretações quase estáticas das relações sociais, respeitando uma "ordem natural", como as expressas por esses estudiosos, ao serem deslocados abrem espaço para que percebamos as diferenças e prováveis choques de interesses. A seguir nos dedicaremos a esta análise.

\section{Diversidade e conflitos nos anfiteatros romanos}

Entre as diversas obras escritas por Suetônio, destacamos a Vida dos Césares. Esse trabalho é, na verdade, uma narrativa da vida de doze imperadores, de Júlio César a Domiciano, e deve ter sido escrito em meados do século II. Ao registrar as vidas dos imperadores romanos, Suetônio menciona seus feitos em diferentes contextos que vão da vida pública até seus amores, em um relato envolvente que trata não só de política como também de paixões, desejos e traições. ${ }^{25}$

Ao narrar a vida de Augusto, Suetônio estabelece comentários acerca da legislação que este imperador teria criado para ordenar as arquibancadas e a obrigação do uso da toga para os cidadãos romanos. Como praticamente todos

24 SUETÔNIO. The lives of the Caesars. Tradução: J.C. Rolfe. Londres: Harvard University Press, 1989, uita de Augusto, XLIV. Coleção Loeb.

25 Sobre como Suetônio elabora seu texto, ver, por exemplo, GARRAFFONI, R. S. O conflito no espaço público: a arena romana em discussão. Boletim do CPA, IFCH/Unicamp, ano 6, n. 11, 2001, p. 65-75. 
os autores mencionam essas duas leis, gostaria de tecer alguns breves comentários sobre elas. Iniciemos pela questão da hierarquização das arquibancadas.

Embora muitos dos estudiosos considerem a atitude de Augusto singular nos modelos interpretativos comentados acima, é importante destacar que este imperador não foi o pioneiro a estabelecer divisões nas arquibancadas de edifícios destinados a espetáculos públicos. De acordo com Orlandi, em 194 a. C. há o primeiro registro da segregação entre senadores e plebs nos teatros, feito transformado em lei somente em 87 a. C. (Lex Roscia Theatralis). ${ }^{26}$ Essa ponderação nos faz pensar que, em um primeiro momento, as diferenciações foram propostas de forma mais ampla, de acordo com o grupo social. Para além disso, tal proposição nos leva a refletir que, em contextos históricos diversos, as distinções sociais nos teatros não foram elaboradas de maneira única e, portanto, tomar a lei de Augusto para um extenso período nos parece uma ampla generalização. Estudiosos como Futrel e Gunderson tomam as distinções de maneira empírica e passam a impressão de que, depois de promulgada a lei por Augusto, todos os anfiteatros já estavam adaptados à nova situação, idéia que Edmondson questiona.

Segundo Edmondson ${ }^{27}$, as primeiras segregações foram propostas para os teatros e, em seguida, foram sendo adaptadas para os anfiteatros de pedra em um processo lento. Seria somente em 80 d. C., com a construção do Amphitheatrum Flavium, posteriormente conhecido como Coliseu, que tais hierarquias se tornariam mais visíveis, pois, além do lugar em que se sentava, outro fator de distinção importante seria o tipo de assento a que a pessoa estava designada.

Tais considerações nos remetem a uma interpretação menos estática das arquibancadas, pois as segregações não seriam estanques e poderiam ser alteradas de acordo com o momento histórico. Raciocínio semelhante poderia ser proposto para o uso da toga pelos cidadãos. Se a toga simbolizava o status daquele homem, isto é, marcava seu local social como cidadão em oposição aos escravos e estrangeiros, cabe-nos questionar quem seriam tais pessoas às quais era permitido tanto o uso de togas como a exibição de acessórios de distinção.

26 ORLANDI, S. I loca del Colosseo. In: LA REGINA, op. cit., p.89-103. Sobre a lei em específico, veja p. 89.

27 EDMONDSON, J.C. Dynamic Arenas: Gladiatorial presentations in the city of Rome and the construction of Roman society during the Early Empire. In: SLATER, W.J. (Org.). Roman theater and society. Michigan: The University of Michigan Press, 1996, p. 69-112. 
De acordo com Funari, há um redimensionamento da questão da cidadania nos dois primeiros séculos do Principado, pois esta foi, aos poucos, expandindo-se e atingindo um número cada vez maior de pessoas. ${ }^{28}$ Embora a cidadania romana fosse a única que permitia plenos direitos, as locais continuavam a ter um importante papel, em especial no que se refere às questões mais restritas. ${ }^{29}$ Neste sentido, é possível afirmar que os cidadãos presentes nas arquibancadas não formavam uma camada homogênea mas, pelo contrário, carregavam suas experiências e interesses particulares.

Da mesma maneira que encontramos brechas na legislação e destacamos a pluralidade de pessoas tituladas de cidadãos romanos, também é possível perceber que a arquitetura dos anfiteatros não era tão rígida como propõem os modelos interpretativos comentados. A noção de que a existência de entradas separadas para elite e plebs determinaria os acessos aos assentos é marcante nesses argumentos, assim como a delimitação dos tipos dos assentos, discutida em menor escala por esses especialistas.

Em nossa opinião, mesmo que houvesse muros para separar e delimitar os espaços, a maneira como as pessoas se organizavam não era única, pois se por um lado estava sujeita a uma lei mais geral, por outro era necessário considerar as estruturas municipais. Neste sentido, a análise dos loca, postos reservados, possibilita uma leitura mais flexível da acomodação das pessoas. Orlandi, por exemplo, ao analisar os loca do Coliseu tece considerações que nos permitiram pensar de maneira menos determinista. ${ }^{30}$ De acordo com seu argumento, o Coliseu, como os demais anfiteatros, fora construído para que diversas categorias de pessoas pudessem freqüentá-lo e tivessem acesso a ele. Em suas arquibancadas encontramos uma série de inscrições em dativo ou genitivo indicando número de pés possíveis para o espaço demarcado. ${ }^{31}$ Há, por exemplo, lugares para cavaleiros (equites romani), jovens (praetextati) ou cidades importantes com as quais Roma mantinha contatos comerciais, como Cádiz (gaditani). ${ }^{32}$

28 FUNARI, P. P. A. A cidadania entre os romanos. In: Pinsky, J.; Pinsky, C. (Orgs.). História da Cidadania São Paulo: Contexto, 2003, p. 49-79.

29 Ibid., p. 66-67.

30 ORLANDI, op. cit.

31 Segundo o autor, se escrito no genitivo deve-se traduzir por "posto de...", já no dativo a tradução seria "posto reservado a...": Ex. Gaditani (posto de pessoas provenientes de Cádiz ou posto reservado a pessoas provenientes de Cádiz).

32 Mencionamos somente o estudo do Coliseu, mas há pesquisas sobre loca em outros anfiteatros romanos. Ver, por exemplo, BELTRÁN MARTÍNEZ, A.; BELTRÁN LLORIS, F., op. cit., p. 25-27. 
Essas marcações se modificam de acordo com o período, assim como as técnicas para a inscrição do lugar reservado, o que indica diferentes concepções dos postos ao longo do tempo. Além disso, destacamos o fato de que, em geral, tais postos são coletivos; só em alguns casos encontramos nome de pessoas, predominando, então, nomes das famílias senatoriais ou das elites locais. Se considerarmos o caráter coletivo dessas inscrições, é possível argumentar que pessoas de diferentes interesses poderiam sentar com certa proximidade, o que permitiria a ocorrência de desavenças. Assim, mesmo que as hierarquias romanas estivessem ali representadas, não podemos descartar a possibilidade dos choques de interesses, sejam eles políticos, comerciais ou passionais. Talvez os grandes exemplos de tais conflitos sejam as desavenças para conseguir os prêmios distribuídos durante os espetáculos ou a famosa briga entre Pompeianos e Nucerinos que explodiu no anfiteatro de Pompéia em 59 d. C. e foi registrada por Tácito, ${ }^{33}$ além de aparecerem referências a ela nas paredes pompeianas, seja em forma de grafites como de pintura.

Este é, portanto, o ponto que gostaríamos de destacar com mais ênfase, pois é o que difere nossa postura da dos estudiosos mencionados. Acreditamos que a maneira como esses especialistas articulam a legislação comentada em Suetônio e a estrutura arquitetônica dos anfiteatros cria uma imagem poderosa que, praticamente, exclui os conflitos. Assim, a base de suas interpretações está em um modelo normativo em que a legislação de Augusto e a estrutura arquitetônica tornam-se fontes sobrepostas para construir uma imagem harmoniosa da sociedade romana na qual os papéis sociais estavam definidos pelos locais ocupados nas arquibancadas.

Em todos os estudos citados há uma utilização da legislação e da cultura material sem mencionar seus contextos específicos, criando quadros explicativos genéricos, muitas vezes tendo o Coliseu como modelo. Essa característica acaba por desconsiderar as variações estruturais dos edifícios e, conseqüentemente, suas particularidades. Segundo Edmondson, os diferentes motivos pelos quais os combates eram realizados são menosprezados nessas interpretações, assim como o local propriamente dito que tal edifício ocupa no interior da cidade. Tanto os motivos como o espaço em que se situava o anfiteatro são elementos fundamentais, pois eles causariam diferentes impactos em quem os presenciava, tornando essa idéia de imposição de um único ethos romano, presente nos argumentos de todos estes autores citados, questionável.

33 TÁCITO. Annals. Tradução: J. Jackson. Londres: Harvard University Press, 1986, (XIV, 17). 
Essa ressalva é, em nossa opinião, fundamental e é com inspiração nela que elaboramos nosso estudo, uma vez que acreditamos que diferentes tipos de edifícios produziam espetáculos diversos, indicando percepções plurais de relações com o espaço e, conseqüentemente, identidades mais heterogêneas, construídas a partir de conflitos e trocas.

Contrapondo o texto de Suetônio à cultura material e respeitando seus contextos históricos, procuramos construir uma interpretação na qual consideramos os anfiteatros como locais onde homens e mulheres de diferentes etnias, idades e condições sociais se encontravam para ver e torcer por seus gladiadores favoritos e manifestavam sua opinião nas decisões. Neste sentido, mesmo que haja locais reservados no anfiteatro, a ocorrência de conflitos não pode ser menosprezada e ressaltá-los indica, também, nossa preocupação em tornar os espectadores menos passivos, isto é, capazes de manifestar suas posturas e serem sujeitos de sua História.

\section{Agradecimentos}

Agradeço a Pedro Paulo Funari (Unicamp) pela orientação da tese de doutorado que originou este artigo. Sou grata também a André Leonardo Chevitarese (UFRJ), Gabriele Cornelli (Unimep), Lourdes Feitosa (NEE Unicamp), Renan e Fátima Frighetto (ambos UFPR), Priscila Nucci (pósgraduação IFCH/Unicamp), Nanci Vieira de Oliveira (Uerj), Gilvan Ventura (Ufes) e Andrés Zarankin (Conicet - Argentina) pela troca de idéias em diferentes momentos. Cabe destacar que a pesquisa de doutorado foi financiada pela Fapesp de março de 2000 a fevereiro de 2004. Foi por meio do apoio dessa instituição que pude pesquisar na Universidad de Barcelona e Universität Heidelberg e entrar em contato com grande parte da bibliografia citada. Assim, sou grata também pela gentileza dos professores Geza Alföldy e Jose Remesal por me receber em suas universidades e permitir o acesso às bibliotecas. A responsabilidade das idéias aqui expressas recai apenas sobre a autora. 